Kumawula, Vol. 3, No.3, Desember 2020, Hal 525 - 532 DOI: https://doi.org/10.24198/kumawula.v3i3.30856

ISSN 2620-844X (online)

Tersedia online di http://jurnal.unpad.ac.id/kumawula/index

\title{
KEWIRAUSAHAAN DAN PEMBERDAYAAN KELOMPOK WANITA TANI - KWT DESA CINUNUK KABUPATEN BANDUNG
}

\author{
Teguh Husodo $^{1^{*}}$, Keukeu Kaniawati Rosada ${ }^{2}$, Mia Miranti ${ }^{3}$, Nining Ratningsih ${ }^{4}$, Suryana ${ }^{5}$ \\ ${ }^{1}$ Departemen Biologi, Fakultas Matematika dan Ilmu Pengetahuan Alam, Universitas Padjadjaran. \\ ${ }^{2}$ Departemen Biologi, Fakultas Matematika dan Ilmu Pengetahuan Alam, Universitas Padjadjaran. \\ ${ }^{3}$ Departemen Biologi, Fakultas Matematika dan Ilmu Pengetahuan Alam, Universitas Padjadjaran. \\ ${ }^{4}$ Departemen Biologi, Fakultas Matematika dan Ilmu Pengetahuan Alam, Universitas Padjadjaran. \\ ${ }^{5}$ Departemen Biologi, Fakultas Matematika dan Ilmu Pengetahuan Alam, Universitas Padjadjaran.
}

*Korespondensi : t.husodo@unpad.ac.id

\begin{abstract}
Micro, small, and medium enterprises are community efforts to empower themselves to create independent business opportunities that rely on the ability and creativity in people's lives. However, the efforts made require the support of various aspects of entrepreneurship to add insight into the manufacturing process and the benefits of the products used and produced. As many as seven of the thirty micro, small, and medium enterprises in Cinunuk Village were divided into six categories and analyzed using nine indicators from the method business model canvas. Other than that, establishing a micro, small, and medium enterprises that can be developed as a potential businesses not only from the economic aspect but also community empowerment aspect. The use of the residents' narrow land, the ease of production with the concept of urban farming is considered capable of becoming a business icon of Cinunuk Village. The female farmer groups' potential will be able to become advanced micro, small, and medium enterprises through support for increased entrepreneurship, such as licensing completeness, pharmacological testing, and certification.
\end{abstract}

\begin{abstract}
ABSTRAK
Usaha Mikro dan Kecil Menengah merupakan usaha masyarakat untuk memberdayakan dirinya dengan tujuan menciptakan peluang usaha mandiri yang mengandalkan kemampuan dan kreativitas dalam kehidupan masyarakat itu sendiri. Namun demikian, upaya yang dilakukan membutuhkan dukungan berbagai aspek kewirausahaan agar menambah wawasan mengenai proses pembuatan dan manfaat dari produk-produk yang digunakan dan dihasilkan. Sebanyak tujuh dari tiga puluh usaha mikro dan kecil menengah Desa Cinunuk yang terbagi kedalam enam katagori telah dianalisis menggunakan sembilan indikator dari metode business model canvas. Selain itu, menetapkan satu usaha mikro dan kecil menengah yang dikembangkan sebagai usaha yang potensial tidak hanya dari aspek ekonomi namun juga pemberdayaan masyarakat. Pemanfaatan lahan sempit milik warga, kemudahaan dalam produksi dengan konsep urban farming dianggap mampu menjadi ikon usaha dari Desa Cinunuk. Potensi kelompok wanita tani Desa Cinunuk akan mampu menjadi usaha mikro dan kecil menengah yang maju melalui dukungan peningkatan kewirausahaan seperti kelengkapan perizinan, uji farmakologi dan sertifikasi.
\end{abstract}

Keywords: Empowerment; Entrepreneurship; Urban Farming

\section{PENDAHULUAN}

Usaha kecil dan informal merupakan sektor usaha yang telah terbukti berperan strategis atau penting dalam mengatasi akibat dan dampak dari krisis ekonomi yang pernah melanda Indonesia di tahun 1997. Di sisi lain, sektor usaha kecil dan informal juga telah mampu memberikan kontribusi dalam mendorong pertumbuhan ekonomi Indonesia selama ini (Sugiarti, Sari, \& Hadiyat, 2020). Kedudukan yang strategis dari sektor usaha kecil dan informal tersebut juga karena sektor ini mempunyai beberapa keunggulan dibandingkan usaha besar/menengah. Keunggulan-keunggulan sektor ini, antara lain 
kemampuan menyerap tenaga kerja, menggunakan sumber daya lokal, serta usahanya relatif bersifat fleksibel sehingga turut membantu menekan angka pengangguran (Sugiarti et al., 2020; Supriyanto, 2006).

Berbagai peran strategis dimiliki sektor UMKM (Usaha Mikro, Kecil, dan Menengah), namun sektor ini juga dihadapkan berbagai permasalahan. Kendala dan permasalahan, antara lain dari aspek permodalan, kemampuan manajemen usaha, dan kualitas sumberdaya manusia pengelolanya. Kendala dan permasalahan usaha kecil dan informal lainnya juga disebabkan karena sulitnya akses terhadap informasi dan sumber daya produktif, seperti modal dan teknologi, yang berakibat menjadi terbatasnya kemampuan usaha kecil untuk berkembang (Supriyanto, 2006).

Mengingat peran strategis UMKM dan masih terbatasnya kemampuan UMKM untuk berkembang, maka saat ini pengembangan usaha kecil merupakan salah satu strategi yang diambil Pemerintah dalam rangka pertumbuhan ekonomi. Dalam rangka pengembangan usaha kecil ini diperlukan informasi yang lengkap, mudah dan cepat dapat diakses, terutama informasi potensi suatu sektor usaha ekonomi atau komoditas untuk dikembangkan pada suatu wilayah tertentu, faktor-faktor yang mempengaruhi pengembangannya, serta prospek pengembangan program kemitraan terpadu untuk sektor usaha atau komoditas tersebut (Supriyanto, 2006).

Walaupun tidak banyak memberikan hasil maksimal terhadap peningkatan kinerja UMKM dan perkembangan ekonomi lebih luas, pengembangan UMKM secara parsial berupaya meningkatkan daya saing mandiri. Diharapkan melalui peningkatan produktivitas UMKM akan berdampak terhadap perbaikan kesejahteraan masyarakat walaupun pada skala lokal. Salah satu alternatif dalam meningkatkan produktivitas tersebut adalah dengan melakukan modernisasi sistem usaha dan dukungan perangkat kebijakan yang sistemik, sehingga memberikan dampak yang lebih luas dalam meningkatkan daya saing daerah. Pengembangan kewirausahaan masyarakat diharapkan menjadi terobosan baru agar dapat mempercepat pencapaian tumbuhnya wirausaha-wirausaha yang mandiri yang memiliki karakter inovatif, tangguh dan berwawasan global (Malik dan Mulyono, 2017). Salah satu alternatif pemecahan masalah adalah melalui kegiatan pemberdayaan dan pendidikan kewirausahaan, guna mengubah sikap mental ketergantungan serta menumbuhkembangkan etos kerja, sehingga diharapkan dapat menumbuhkan kemandirian (Sukidjo, 2012).

Desa Cinunuk Kecamatan Cileunyi Kabupaten Bandung merupakan salah satu desa yang sedang mengembangkan produk UMKM. Pengembangan UMKM ditargetkan menjadi usaha yang tidak hanya dikenal pada tingkat lebih tinggi, namun UMKM tersebut merupakan usaha mandiri masyarakat yang melibatkan banyak warga didalamnya. Mengacu kepada hal tersebut, maka riset pengabdian kepada masyarakat ini bermaksud meningkatkan apa yang telah dilaksanakan oleh masyarakat selama ini melalui upaya pencapaian sertifikasi produk Disperindag, sertifikasi layak konsumsi BPOM, dan Sertifikasi Halal Depag untuk bidang kuliner. Untuk itu, riset PKM ini dibagi menjadi tiga tahap, yaitu identifikasi dan analisis bisnis UMKM, penepatan UMKM yang akan dikembangkan, dan analisis business plan dan pengembangan usaha dari UMKM yang dianggap memenuhi kriteria pengembangan. Selain itu, program sosialisasi tentang standarisasi juga dilakukan, sehingga dapat memberi informasi dalam menghadapi persaingan di masa yang akan datang, serta pengetahuan berwirausaha yang berhubungan dengan etika bisnis, menangani keluhan pelanggan dan cara mengelola keuangan yang baik.

\section{METODE}

\section{Desain}

Riset pengabdian kepada masyarakat (PPM) ini dilaksanakan menggunakan metode kualitatif dengan khalayak sasaran adalah para pelaku UMKM (Usaha Mikro 
Kecil Menengah) di Desa Cinunuk, Kecamatan Cileunyi Kabupaten Bandung serta pemangku kepetingan yang terlibat dan mempengaruhi keberlanjutan dari pelaku UMKM.

\section{Metode Pengumpulan Data}

Secara umum, desain PPM ini menggunakan metode kualitatif dan dengan teknik pengumpulan data yaitu survei. Data dikumpulkan melalui dua tahap kerja. Pertama adalah wawancara dengan pihak Pejabat Desa, seperti Kepala Desa dan Kasie Urusan Kesejahteraan Masyarakat. Kedua, berdasarkan informasi dari Pejabat Desa, maka dilakukan pengumpulan data kepada para pelaku UMKM di Desa Cinunuk. Pada tahap awal tidak kurang dari 30 UMKM yang telah terdaftar di Desa Cinunuk, tiga Kelompok Wanita Tani (KWT) dan beberapa pengusaha lainnya yang belum terdaftar. Untuk memudahkan kategorisasi dalam unit sampel, maka UMKM Desa Cinunuk dibagi berdasarkan kategori ragam usaha, yaitu kelompok usaha makanan/kuliner, kelompok usaha produksi hasil pertanian/perikanan dan kelompok usaha industri.

\section{Kegiatan PPM}

Selama proses identifikasi karakteristik UMKM, dilakukan pengumpulan data dengan wawancara kepada para pelaku UMKM Desa Cinunuk berdasarkan informasi dari Pejabat Desa Cinunuk. Untuk mendapatkan data komprehensif terkait dengan kegiatan UMKM juga dilakukan Focus Discuss Group (FGD) yang melibatkan berbagai pemangku kepentingan, seperti pelaku UMKM, lembaga pemerintahan desa, dan pihak eksternal lainnya. Kegiatan pelaksanaan pengabdian PPM Kewirausahaan ini dilaksanakan dalam bentuk lokakarya dan pelatihan kewirausahaan kepada pelaku UMKM (Usaha Mikro Kecil Menengah)
Desa Cinunuk, Kecamatan Cileunyi Kabupaten Bandung.

\section{Rancangan Evaluasi}

Sesuai dengan rancangan kerja pelaksanaan PPM, maka evaluasi kegiatan yang dilaksanakan kedalam tiga tahap, yaitu;

a) Tahap perencanaan kegiatan. Pada awal kegiatan, tim pelaksana dengan para mahasiswa mengundang para anggota pelaku UMKM di kantor desa. Selanjutnya, tim pelaksana menentukan sasaran pelatihan ini adalah masyarakat desa pelaku UMKM yang berada di lingkungan.

b) Selama proses kegiatan. Evaluasi pada tahap ini ditujukan untuk mengetahui tingkat pemahaman para peserta pelatihan disertai umpan balik berupa pertanyaan-pertanyaan dari para peserta undangan yang telah mendapatkan transfer pengetahuan terkait kewirausahaan dan strategi bisnis serta pemasaran produk unggulan.

c) Tahap akhir kegiatan. Evaluasi pada akhir kegiatan ini dilakukan untuk mengukur keberhasilan dari seluruh program pelatihan. Adapun indikator keberhasilan dari kegiatan ini ditetapkan $80 \%$ peserta dalam kegiatan pelatihan ini dapat memahami teknik kewirausahaan, strategi bisnis, dan pemasaran produk yang akan dijual kepada pelanggan.

\section{Lokasi Kegiatan PPM}

Adapun lokasi kegiatan PPM Kewirausahaan ini dilaksanakan di Desa Cinunuk, Kecamatan Cileunyi Kabupaten Bandung, Jawa Barat.

\section{HASIL DAN PEMBAHASAN}

Sesuai dengan metode penelitian yang digunakan, maka tahapan pertama dari kegiatan PPM ini adalah mengenai perencanaan, observasi dan survei. Pelaksanaan dimulai pada 
minggu pertama dari empat minggu waktu PPM direncanakan. Hasil yang diperoleh adalah dari 30 UMKM, tiga KWT (Kelompok Wanita Tani) dan tiga Usaha Industri Kecil Sangkar Burung teridentifikasi. Berdasarkan data tersebut, maka UMKM Desa Cinunuk dikelompokkan kedalam empat kategori, yaitu UMKM makanan/kuliner, UMKM kerajinan tangan, dan KWT berbasis pertanian pada lahan kosong dan industri kecil. Pada setiap kategori, tersampel tujuh UMKM (Tabel 1) yang menggunakan pendekatan Business Model Canvas (BMC) sebagai strategi manajemen, berupa visual chart yang terdiri dari sembilan elemen (Amalia, 2019).

Berdasarkan pendekatan indikator model bisnis Osterwalder and Pigneur (2012), setelah dilakukan pemberian bobot (score) kinerja tujuh dari 30 UMKM yang diobservasi, hasil menunjukkan bahwa Echa-Pratama dan Ibu-Nafifa memiliki nilai terbesar. Hal tersebut sesuai dengan tahap pertama, berdasarkan indikator penilaian yang terbagi ke dalam enam kelompok, yaitu online marketing, legalitas, omset, cakupan pemasaran, dan offline marketing. Selanjutnya, kami olah poin-poin yang ada menjadi presentase untuk memberikan peringkat terhadap usaha-usaha tersebut. Berdasarkan data yang telah kami olah, dapat dilihat bahwa usaha kue kering dan basah yang dimiliki oleh Ibu Nafifa memiliki presentase tertinggi, yaitu $76 \%$, sedangkan usaha tanaman hidup (bunga telang, mint, rosemary, rosella) dan sayuran (bawang) yang dimiliki oleh KWT (Kelompok Wanita Tani Bunga Telang) memiliki presentase terendah yaitu $29 \%$.

Berdasarkan pertimbangan dari pihak pemerintah desa bahwa UMKM yang dikembangkan harus memiliki nilai perlibatan masyatakat yang besar, sehingga dapat diangkat sebagai ikon desa dan bersifat padat karya dengan modal usaha yang rendah. UMKM KWT Bunga Telang dianggap memiliki kriteria-kriteria tersebut (Tabel 1). Melalui indikator Osterwalder and Pigneur (2012) yang tidak terpenuhi, pengembangan KWT Bunga Telang sebagai UMKM andalan membutuhkan upaya lebih agar dapat memenuhi apa yang diinginkan oleh Pemerintah Desa Cinunuk. Pemilihan jenis usaha ini juga dipertimbangkan berdasarkan beberapa faktor lain, yaitu

a) Bunga telang berpotensi menjadi produk oleh-oleh khas Desa Cinunuk karena produk olahan bunga telang jarang ditemukan di tempat lain. Suatu daerah sebaiknya memiliki suatu produk komoditas utama, namun Desa Cinunuk belum memiliki hal tersebut, sehingga kami rasa bunga telang mempunyai potensi yang besar untuk menjadi produk oleh-oleh atau produk komoditas utama Desa Cinunuk.

b) Semua warga dapat turut serta berpartisipasi dalam pengembangbiakan tanaman bunga telang untuk dijadikan suatu komoditi usaha dikarenakan proses tanam dan perolehan bibit tanaman bunga telang ini sangat mudah, dan tidak memerlukan lahan yang luas, sehingga dapat dilakukan di pekarangan warga. Selain itu, sudah terdapat usaha yang dapat dijadikan acuan.

c) Berdasarkan tabel indikator usaha yang telah kami olah, usaha minuman herbal Bunga Telang dari KWT Bunga Telang di Desa Cinunuk mendapatkan persentase paling rendah dibandingkan usaha-usaha lainnya.

d) Mensosialisasikan perkembangan dunia digital dan internet untuk berbagai jenis usaha. Saat ini, penggunaan media sosial sebagai media pemasaran produk usaha sudah semakin marak (Susanti, Gunawan, \& Sukaesih, 2019), sehingga kami merasa perlu untuk memperluas platform penjualan dari produk minuman herbal dari KWT kepada berbagai $e$ commerce yang ada di internet serta pengembangan produk dari manajemen media sosial. 
Tabel 1. Penetapan UMKM Terpilih Menggunakan Penilaian Berdasarkan Indikator

\begin{tabular}{|c|c|c|c|c|c|c|c|c|c|}
\hline \multirow[t]{2}{*}{ No } & \multirow[t]{2}{*}{ UMKM } & \multirow[t]{2}{*}{ Jenis Usaha } & \multicolumn{2}{|c|}{ Marketing } & \multirow[t]{2}{*}{ Legalitas } & \multirow[t]{2}{*}{ Omset } & \multirow[t]{2}{*}{ Cakupan } & \multirow[t]{2}{*}{ Produk } & \multirow{2}{*}{$\begin{array}{l}\text { Total } \\
\text { Score (\%) }\end{array}$} \\
\hline & & & Online & Offline & & & & & \\
\hline 1 & Amos's Fish & Ikan Konsumsi & 1 & 2 & 0 & 3 & 2 & 3 & 33 \\
\hline 2 & ASP Jaya & Sangkar Burung & 2 & 3 & 0 & 4 & 4 & 3 & 54 \\
\hline 3 & Echa-Pratma & Handy-Craft & 3 & 5 & 0 & 5 & 4 & 1 & 71 \\
\hline 4 & Ibu-Nafifa & $\begin{array}{l}\text { Kue } \\
\text { Kering/Basah }\end{array}$ & 4 & 5 & 0 & 5 & 2 & 2 & 76 \\
\hline 5 & Paycha & $\begin{array}{l}\text { Kue } \\
\text { Kering/Basah }\end{array}$ & 1 & 1 & 0 & 5 & 2 & 2 & 37 \\
\hline 6 & $\begin{array}{l}\text { KWT Bunga } \\
\text { Telang }\end{array}$ & $\begin{array}{l}\text { Urban Farmyng } \\
\text { System }\end{array}$ & 1 & 2 & 0 & 2 & 2 & 1 & 29 \\
\hline 7 & $\begin{array}{l}\text { Tropical } \\
\text { Yogurt }\end{array}$ & Yoghurt & 2 & 2 & 0 & 2 & 2 & 3 & 34 \\
\hline
\end{tabular}

Melihat besarnya potensi yang dapat dihasilkan dari usaha yang dilakukan oleh pihak KWT Bunga Telang, kegiatan PPM berencana membantu dalam mengembangkan usaha minuman herbal sebagai UMKM. Secara ekonomi, KWT Bunga Telang dapat berkembang dan mengangkat nama desa dari usaha kegiatan UMKM tersebut. Untuk itu, tahap kedua dari PPM ini adalah melakukan analisis usaha bunga telang dari KWT Bunga Telang, melalui pendekatan Business Model Canvas (BMC) sebagai strategi manajemen berupa visual chart. Dengan menggunakan model bisnis ini, kegiatan lokakarya ini dilakukan untuk menyampaikan ide usaha kepada beberapa pihak penting di Desa Cinunuk yang telah hadir, diantaranya Perangkat Desa Cinunuk, BPD Cinunuk dan Anggota, LPMD Cinunuk dan Anggota, dan Tim Pendamping Dana Desa. Adapun sembilan elemen tersebut adalah Customer Segment, Value Proportions, Channels, Revenue Streams, Key Resource, Customer Relationship, Key Activities, Key Partnership, dan Cost Structure (Amalia, 2019).

Tabel 2. Sembilan Indikator Pengembangan Bunga Telang Desa Cinunuk

\begin{tabular}{|c|c|c|c|c|}
\hline Key Partners & Key Activities & $\begin{array}{c}\text { Value } \\
\text { Propositions }\end{array}$ & $\begin{array}{c}\text { Costumer } \\
\text { Relationships }\end{array}$ & Costumer Segment \\
\hline $\begin{array}{l}\text { Pemilik Café dan } \\
\text { Resto } \\
\text { Pemilik Toko Oleh - } \\
\text { Oleh } \\
\text { Pemilik } \\
\text { Supermarket } \\
\text { Reseller } \\
\text { Supplier }\end{array}$ & $\begin{array}{l}\text { Produksi 4M (Man, } \\
\text { Material, Method, } \\
\text { Money) } \\
\text { Promotion } \\
\text { Key Resources }\end{array}$ & $\begin{array}{l}\text { Mengenalkan } \\
\text { Khasiat Produk } \\
\text { Herbal } \\
\text { Meningkatkan } \\
\text { Daya Saing Produk } \\
\text { Khas Cinunuk } \\
\text { Mengenalkan } \\
\text { kebiasaan urban } \\
\text { farming }\end{array}$ & $\begin{array}{l}\text { Channels } \\
\text { E-Commerce } \\
\text { Media Sosial } \\
\text { Toko Oleh - Oleh } \\
\text { Supermarket } \\
\text { Toko Bahan } \\
\text { Organik }\end{array}$ & $\begin{array}{l}\text { Pecinta Produk } \\
\text { Oranik } \\
\text { Pengobatan Herbal } \\
\text { Vegetarian } \\
\text { Pengunjung Café } \\
\text { atau Reseller }\end{array}$ \\
\hline
\end{tabular}

\section{Cost Structure}

Biaya produksi (biaya bahan baku, biaya tenaga kerja, langsung dan biaya overhead)

Biaya promosi

Biaya kemasan

Biaya umum

\section{Revenue Streams}

Penjualan Bunga Telang Kering, Rosemary, Peppermint, dan Rosecella 
Sesuai dengan tahapan kerja, maka dilakukan beberapa kegiatan pada UMKM yang akan dianalisis usaha pengembangannya sebagai berikut:

a. Pemasaran produk bunga telang ke kafe-kafe dalam bentuk bunga yang adanya usaha yang dapat dijadikan sebagai acuan serta melihat besarnya potensi yang dihasilkan dari usaha ini menjadi alasan mereka tertarik untuk ikut mengembangkan usaha bunga telang ini.

Menurut Imayanti, dkk., (2019), studi
Sumber Bahan : KWT RW 05 RT 07 Ds Cinunuk.

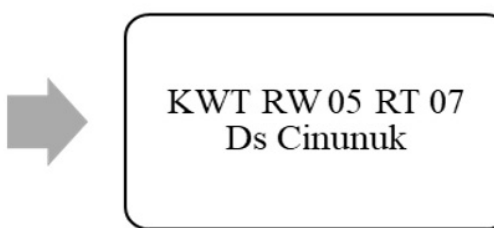

Konsumen:
Mendapatkan
Kemasan Bunga
Telang tanpa
penjelasan informasi
lebih lanjut
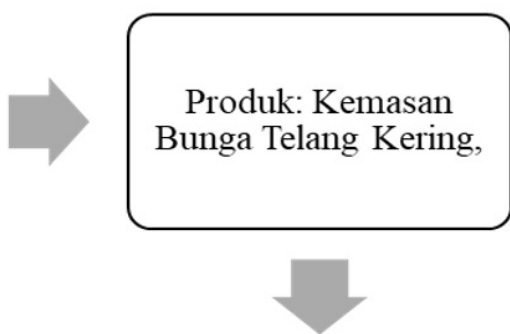

Pasar: hanya dalam bazaar dan beberapa cafe (dibawah 5) berlokasi di Bandung

\section{Gambar 1. Desain alur produksi pemasaran bunga telang oleh KKN KWU Desa Cinunuk}

sudah dikeringkan.

b. Mengunjungi kafe di Jatinangor, Kafe Banyuwangi di Ciseke Besar untuk memperkenalkan teh bunga telang.

c. Membuatkan akun media sosial untuk memasarkan produk bunga telang dengan jangkauan yang luas.

d. Membantu memasarkan produk dengan melakukan pengujian rasa the bunga telang kepada masyarakat.

e. Mengajak warga Desa Cinunuk untuk ikut berpartisipasi dalam pengembangan usaha bunga telang dan memberikan peluang serta membuka lapangan kerja bagi para warga (Gambar 2 dan Tabel 2).

Selama kurang lebih satu bulan, kami melaksanakan kegiatan KKN ini, kami melihat warga Desa Cinunuk cukup antusias untuk berpatisipasi dalam pengembangan usaha bunga telang. Banyak ibu rumah tangga yang ingin berpatisipasi dalam pengembangan usaha bunga telang untuk dijadikan suatu komoditi usaha. Selain itu, mudahnya implementasi dalam pengembangan bunga telang dan sudah sebelumnya di Swiss German University (SGU) oleh Maruli Padjaitan mengungkapkan bahwa ekstrak bunga telang dapat dimanfaatkan sebagai obat diabetes, setelah mengonsumsi ekstraknya selama 20 minggu. Menurut (Widiawati, 2019) bunga telah sebagai salah satu tanaman herbal yang memiliki kandungan farmakologi dalam cakupan luas, yaitu antimikroba, antioksidan, antikanker, dan antidiabetes.

Adapun rencana tindak lanjut dalam pengembangan usaha ini adalah dengan memasok bunga serta memberi informasi atau pengetahuan produk bunga telang mengenai manfaat dan cara pengolahannya kepada pemilik kafe. Selain itu, melalui urban faming di desa tersebut, agar dapat memanfaatkan lahan-lahan yang tersedia. Langkah yang dilakukan adalah dengan memberikan kuesioner pada warga Desa Cinunuk yang berminat untuk berpartisipasi dalam mengembangkan usaha bunga telang.

Adapun hambatan yang dihadapi dari bunga telang ini mengenai harga hasil panen dari bunga telang yang cukup tinggi dan 
ketahanan produknya masih kurang baik, sehingga untuk mengantisipasi dan menanggulanginya tiap Rukun Warga (RW) harus diadakan posko bunga telang agar lebih efisien dan efektif (Gambar 1). Langkahlangkah yang dilakukan dapat dilihat pada Gambar 2. lingkungan masyarakat Desa Cinunuk dan sekaligus menjadi produk komoditas (ikon) Desa Cinunuk. Produk teh bunga telang dapat menjadi suatu usaha yang memanfaatkan lahan sempit milik warga atau lahan kosong di lingkungan Desa Cinunuk yang dapat mendukung program

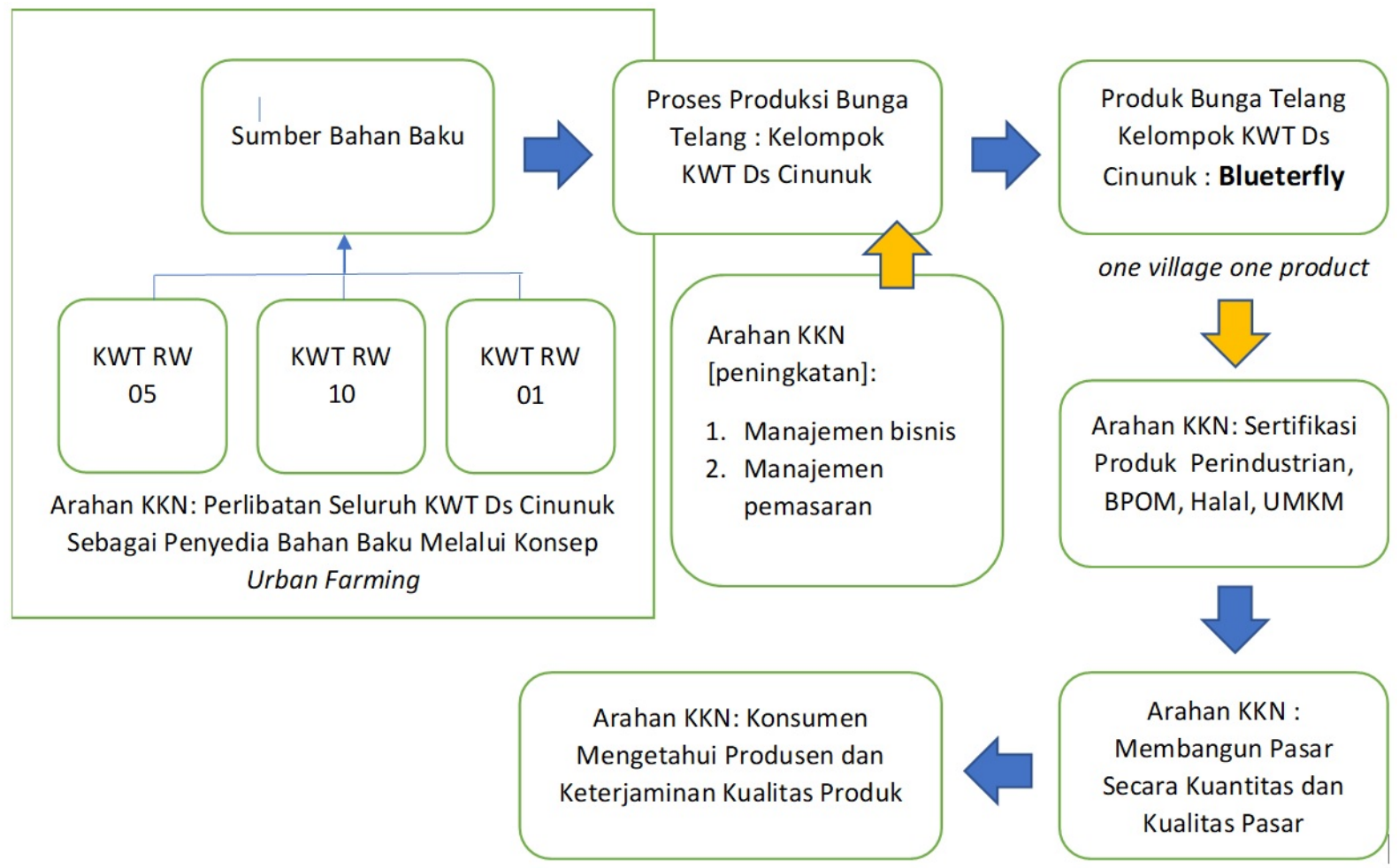

Gambar 2. Desain Baru Alur Produksi Pemasaran Bunga Telang oleh KKN KWU Desa

\section{SIMPULAN}

Desa Cinunuk memiliki potensi UMKM yang dijalankan oleh warganya. Namun berdasarkan analisis usaha pengembangan UMKM bahwa tidak semua usaha tersebut dapat dikembangkan, khususnya ketika ditantang menjadi ikon desa. Dari tujuh UMKM yang dianalisis, usaha teh bunga telang yang dijalankan oleh KWT merupakan salah satu usaha yang dapat memenuhi hampir seluruh kriteria tersebut. UMKM KWT bunga telang potensial dikembangkan sebagai usaha kuliner yang dikonsumsi dalam bentuk minuman. Pengembangan usaha ini relatif sederhana dan dapat dibudidayakan di urban farming yang digencarkan oleh pemerintah desa.

\section{UCAPAN TERIMAKASIH}

Terimakasih disampaikan kepada mahasiswa peserta KKN KWU angkatan 2019-2020 yang telah membantu dalam pengumpulan data dan pelaksanaan FGD di Desa Cinunuk. Pembiayaan dari pelaksanaan PPM Kewirausahaan ini berasal dari Dana Pengabdian Kepada Masyarakat DRPM Universitas Padjadjaran. 


\section{DAFTAR PUSTAKA}

Amalia, D. 2019. 9 Elemen yang Harus Ada dalam Bisnis Model Kanvas. Retrieved from https://www.jurnal.id/id/blog/2018 -memahami-tentang-bisnis-modelkanvas/., Ddiakses 30 Juni 2020.

Imayanti, R. A., Rochmah, Z., Aisyah, S. N., Alfaris, M. R. 2019. Pemberdayaan Masyarakat dalam Pengolahan Bunga Telang di Desa Panggreh Kecamatan Jabon, Kabupaten Sidoarjo. Conference on Innovation and Application of Science and Technology (CIASTECH 2019) Universitas Widyagama Malam. ISSN: 26221284.

Malik, A. and dan Mulyono, S. E. 2017. Pengembangan Kewirausahaan Berbasis Potensi Lokal melalui Pemberdayaan Masyarakat. Journal of Nonformal Education and Community Empowerment. 1(1) 87101.

Osterwalder, A. and Pigneur, Y. 2012. Business Model Generation. Elex Media Komputindo. Jakarta. A. (2012)

Sugiarti, Y., Sari, Y., \& Hadiyat, M. A. (2020). Peranan E-Commerce untuk Meningkatkan Daya Saing Usaha Mikro Kecil dan Menengah (UMKM) Sambal di Jawa Timur. Jurnal Kumawula: Jurnal Pengabdian Kepada Masyarakat, 3(2), 298-309. https://doi.org/https://doi.org/10/2419 8/kumawula.v3i2.28181

Sukidjo. 2012. Peran Pendidikan Kewirausahaan dalam Pemberdayaan Masyarakat Miskin di Indonesia. Jurnal Economia. 8(1) 33-41.

Supriyanto. (2006). PEMBERDAYAAN

USAHA MIKRO, KECIL, DAN

MENENGAH (UMKM) SEBAGAI
SALAH SATU UPAYA

PENANGGULANGAN

KEMISKINAN. Jurnal Ekonomi \&

Pendidikan, 3(1). Retrieved from

http://journal.uny.ac.id/index.php/jep/

article/download/627/490

Susanti, S., Gunawan, W., \& Sukaesih. (2019). Pengembangan Pemasaran Bordir dan Kelom Geulis Tasikmalaya Melalui Media Sosial. Jurnal Kumawula: Jurnal Pengabdian Kepada Masyarakat, 2(3), 248-261.

https://doi.org/http://10.24198/kumaw ula.vli3.25256

Widiawati, K. 2019. Penerapan Digital Marketing sebagai Pendukung Sociopreneur Teh Bunga Telang (Butterfly Pea Tea). Jurnal Administrasi Kantor, Vol. 7, No. 2: 215-224. P-ISSN: 2337-6694 EISSN: 2527-9769. 